\title{
Hair growth activity of seeds and fruit pulp of Eugenia jambolana (Jamun)
}

\begin{abstract}
Objective: Alopecia is a psychologically distressing condition. Androgenetic alopecia, which affects millions of men and women, is an androgen-driven disorder. This paper evaluates the use of Eugenia jambolana seeds and fruit pulp for hair growth activity.

Aim: The present study was aimed to investigate the efficacy of seeds and pulp extracts of Eugenia jambolana as a potential hair growth promoter.

Method: Ethanolic extracts of seeds and fruit pulp were incorporated in oleaginous base that was applied topically on shaved skin of albino mice. Albino mice were screened for hair growth activity, on four parameters; the hair initiation time, hair completion time, hair length and hair count. Treated groups were compared with $2 \%$ ethanolic solution of minoxidil.
\end{abstract}

Result: From this study, it can be concluded that the ethanolic extract of fruit pulp exhibited more pronounced effects when compared to the seeds extract.

Conclusion: The generated data proved that the Eugenia jambolana fruit pulp extract exhibit a significant potency in promoting hair growth.

Keywords: eugenia jambolana, alopecia, hair growth activity
Volume 2 Issue 6 - 2015

\author{
Neetu Gautam, Sakshi Sehgal,Vineet Gupta \\ Rajiv Gupta \\ Department of Pharmacy, Babu Banarasi Das National Institute \\ of Technology \& Management, India
}

\begin{abstract}
Correspondence: Rajiv Gupta, Professor and Dean, School of Pharmacy, BBD University, Lucknow- 226028, India, Tel +9l 9839278227,Email rajiv961@rediffmail.com
\end{abstract}

Received: October 31, 2014 | Published: November 23, 2015

\section{Introduction}

Hair is the characteristic covering of mammalian skin which originates from embryonic ectoderm. In humans, the main function of the hair is mainly related to appearance. ${ }^{1}$ Various factors like genetic predisposition and hormonal factors have predominantly contributed to the major reason of hair fall. ${ }^{2}$ Alopecia, one of the chronic inflammatory disease, affects the hair follicles and it can affect men, women or children at any age. The etiology and subsequent development of alopecia is not fully understood, but it is an autoimmune disorder that arises as a combination of genetic and environmental influences. ${ }^{3}$ Hormonal variations are also considered to be the main cause of androgenetic alopecia. ${ }^{4}$ The age at onset of androgenetic alopecia in men varies, but occurs on average in men in their mid-20s. The prevalence and severity of androgenetic alopecia in men increase directly with age. ${ }^{5}$ The use of natural products in cosmetics is increasing at a high rate and about 1000 kinds of plant extracts have been examined with respect to hair growth activity. In the traditional Indian system of medicine, many plants and herbal formulations are reported for hair growth promotion as well as improvement of quality of hair, but lack of sound scientific backing and information limits their usage with confidence. ${ }^{6}$ The present study is an effort to formulate and evaluate hair growth promoting activity of the formulation of fruit and seed extracts of Eugenia jambolana.

\section{Material and method}

\section{Plant material}

The fruits and seeds of Eugenia jambolana (Jamun) were collected from Lucknow and were authenticated by Division of Taxonomy, NBRI, Lucknow, with ref no. NBRI/CIF/130/2010. The powdered plant part was subjected to pharmacognostic studies for confirmation.
Physicochemical properties of powdered crude drug: Powdered plant parts were subjected to proximate analysis including Moisture content, total ash, acid insoluble ash, water soluble ash, water insoluble ash and sulphated ash. The extracts obtained from successive solvent extractions were then subjected to qualitative chemical analysis for identification of various plants constituents using different methods. Thin layer chromatography with different mixtures of solvent systems were performed to confirm the presence of constituents detected in qualitative chemical test. ${ }^{7,8}$

Preparation of extracts: The fruit and seeds were dried, crushed to moderately coarse power and stored in airtight container. The dried powdered drugs were successively extracted using petroleum ether, ethyl acetate, ethanol and water using Soxhlet extractor until completely exhausted. ${ }^{9-11}$ The solvent from the extract was eliminated under reduced pressure and dried extracts were collected. The percentage yield for the extracts was as given in Table 1. The ethanolic extract of the individual parts were found to be most effective when compared with the other extracts.

Preparation of formulation: The ethanolic extracts were incorporated into hair cream base for the preparation of ointment by using fusion method with $\mathrm{o} / \mathrm{w}$ base. ${ }^{12}$ The ointment base consisted of white soft paraffin $(90 \%)$, cetosteryl alcohol (5\%), bees wax $(20 \%)$ and hard paraffin $(3 \%)$.

\section{Animals}

Wistar strain albino mice of either sex weighing 120 to $150 \mathrm{~g}$ were fed on standard diet and water ad libitum. The animals were housed at room temperature $\left(25 \pm 1^{\circ} \mathrm{C}\right)$, relative humidity $45-55 \%$ and a 12:12hrs light/dark cycle. The protocol followed was approved by the Institutional Animal Ethics Committee (IAEC) under CPCSEA committee (BBDNITM/IAEC/21/2010) pre the start of animal 
experimentation. Hair growth studies were carried out on mice that were divided into four groups of five animals each. Mice of group I and II were treated with solvent extracts formulations $(5 \% \mathrm{w} / \mathrm{w}$ ointments) respectively, Group III were treated with standard ( $2 \%$ ethanolic solution of minoxidil) and Group IV control (Figure 1-4).

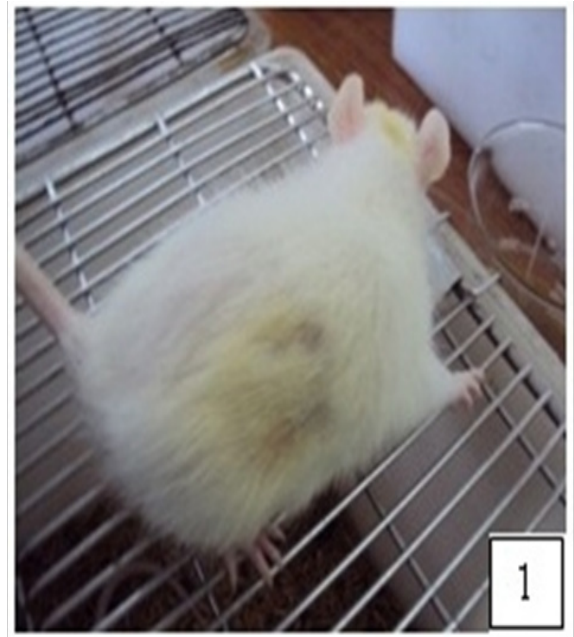

Figure I Fruit pulp ointment treated rat.

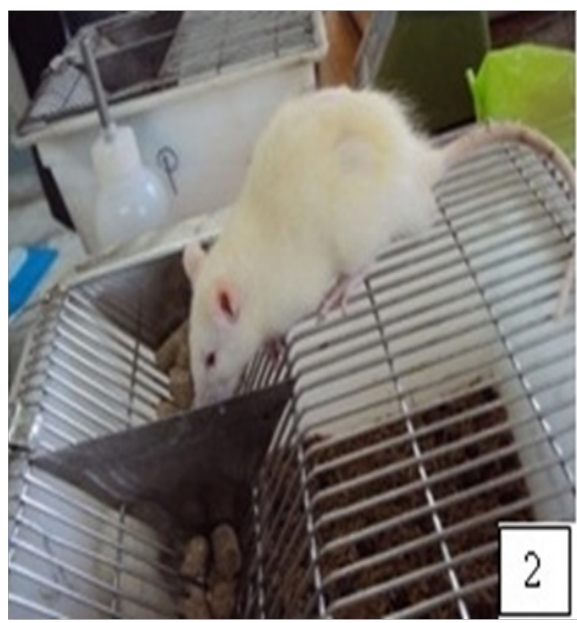

Figure 2 Minoxidil solution treated rat.

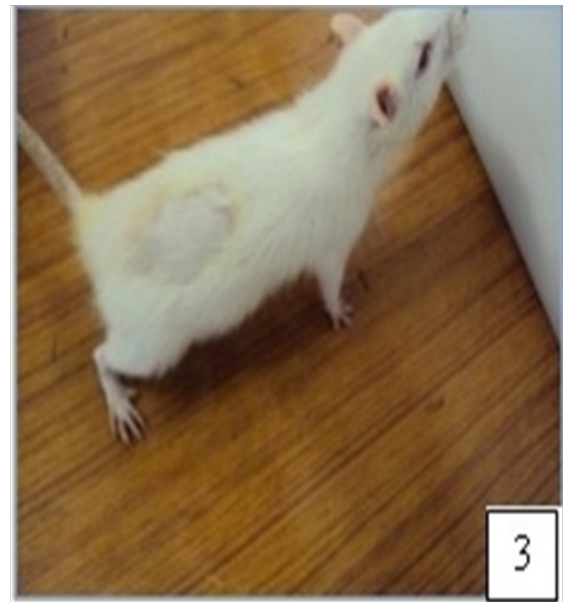

Figure 3 Seed ointment treated rat.

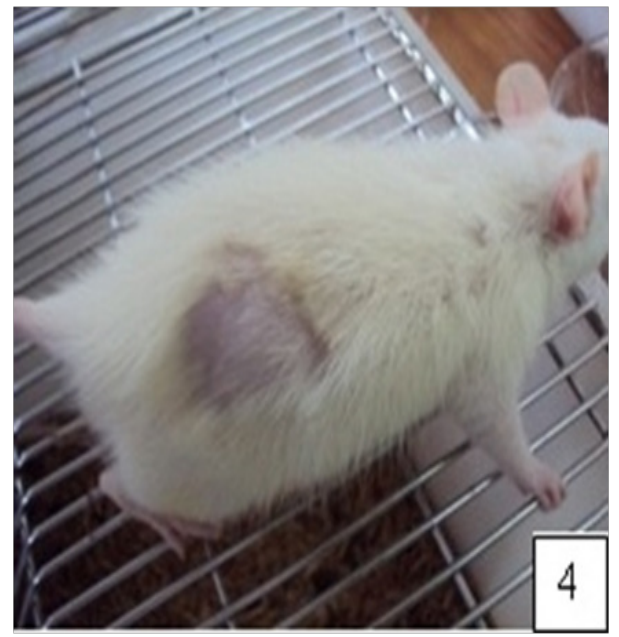

Figure 4 Contol rat.

Table I Percentage yields of extracts

\begin{tabular}{llll}
\hline & & \multicolumn{2}{l}{ Value(s) \% } \\
\cline { 3 - 4 } \begin{tabular}{l} 
No. \\
\cline { 3 - 4 }
\end{tabular} & Extract & Fruit Pulp & Seeds \\
\cline { 3 - 4 } & & $\begin{array}{l}\text { Successive } \\
\text { Extraction }\end{array}$ & Successive Extraction \\
\hline 1. & Pet Ether & $0.85 \%$ & $0.45 \%$ \\
2. & $\begin{array}{l}\text { Ethyl } \\
\text { 3.etate }\end{array}$ & $8.4 \%$ & $3.11 \%$ \\
3. & Ethanol & $4.32 \%$ & $8.62 \%$ \\
\hline
\end{tabular}

Preliminary skin irritation test: The ethanol extract of dried fruit pulp and seeds of Eugenia jambolana were investigated for primary skin irritation test. Hair from the dorsal side of the mice was removed using hair clippers and electrical shavers. A commercially available hair remover (Brand $\mathrm{V}^{*}$ ) was applied for complete removal of hair from $1 \mathrm{sq} \mathrm{cm}$ area. The shaved area was cleaned with surgical spirit and the animals did not show any toxic effects when the ethanol extract was applied in a concentration of up to $10 \%$ for 48 hours post application. Hence the prepared extracts were considered safe for topical application. ${ }^{13}$

Application of test formulation: Hair remover (Brand $\mathrm{V}^{*}$ ) was used to ensure complete removal of hairs from denuded area. Finally, denuded skin was wiped off with surgical spirit. Equal quantities of prepared ointments and standard solution were applied to the denuded area of albino mice once a day for 21 days. The number of hair strands and hair length was measured on day 7, 14 and $2^{14}$ Hair growth initiation and completion time was recorded for each group of animals and was compared with control.

Qualitative hair growth study: Qualitative hair growth analysis was undertaken by visual observation of two parameters: hair growth initiation time (i.e. minimum time to initiate hair growth on denuded skin region) and hair growth completion time (i.e., minimum time taken to complete cover the denuded skin region with new hair). ${ }^{15,16}$

Hair length studies: Hair length was considered to be an important 
factor for hair growth. Manual measurement of the plucked hair was carried out by holding the hair against the ruler, with the aid of magnification lens. ${ }^{17}$ Random samples (15-20) from each group were measured and were averaged.

\section{Result}

For the hair growth activity, four parameters were chosen; the hair initiation time, hair completion time, hair length and hair count. The hair initiation time of pulp extract was less than the control. The order of the treated groups are pulp $<$ standard $<$ seeds $<$ control (Table 2) (Figure 5). The order of the hair length of the treated groups is pulp $>$ standard $>$ seeds $>$ control (Table 3) (Figure 6). The hair count of the treated groups was in the following order; pulp $>$ standard $>$ seeds $>$ control (Table 4) (Figure 7). The formulation of the pulp and seeds are also prepared in the form of ointment. The ointment was prepared by using the Fusion method. The ointment was also characterized with regards to color, odor and taste. It was also evaluated on parameters like penetration, compatibility with skin secretions, primary skin irritation test, emollient properties, ease of application and removal and consistency (Table 5). Firstly, the hair growth activity of the pulp and seeds parts was compared, in which the pulp shows the better results than the seeds. After this, from the pulp part, an ointment was formulated, which was compared with the marketed formulation [Brand $\mathrm{M}^{*}(2 \%$ Minoxidil)]. The results indicated that ointment prepared from the pulp part showed good result than the marketed product.

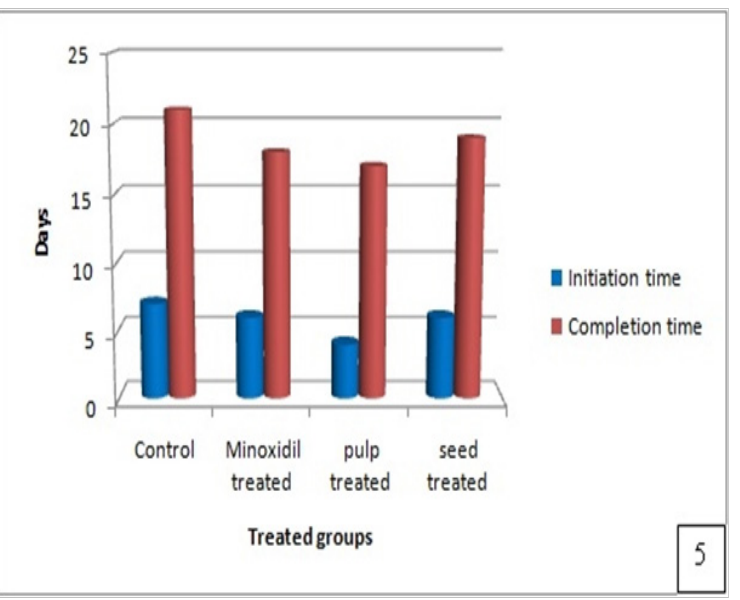

Figure 5 Graph showing the initiation and completion time of the treated groups.

Table 2 Effect of extracts ointments on the hair initiation and completion time

\begin{tabular}{llll}
\hline S. No. & Formulation & \multicolumn{2}{l}{ Hair Growth (Days) } \\
\cline { 3 - 4 } & & Initiation Time & Completion Time \\
\hline 1 & Control & $7 \pm 0.447$ & $21 \pm 0.548$ \\
2 & Minoxidil (2\%) & $6 \pm 0.447$ & $18 \pm 0.447^{*}$ \\
3 & $\begin{array}{l}\text { Pulp (Ethanolic } \\
\text { Extract) }\end{array}$ & $4 \pm 0.632^{*}$ & $17 \pm 0.632^{*}$ \\
4 & $\begin{array}{l}\text { Seeds (Ethanolic } \\
\text { Extract) }\end{array}$ & $6 \pm 0.316$ & $19 \pm 0.707$ \\
\hline
\end{tabular}

Results are expressed as Mean+SEM, $n=5 * \mathrm{P}<0.01$ when group were compared to control group by one way ANOVA, following Dunnet's multiple comparison test.

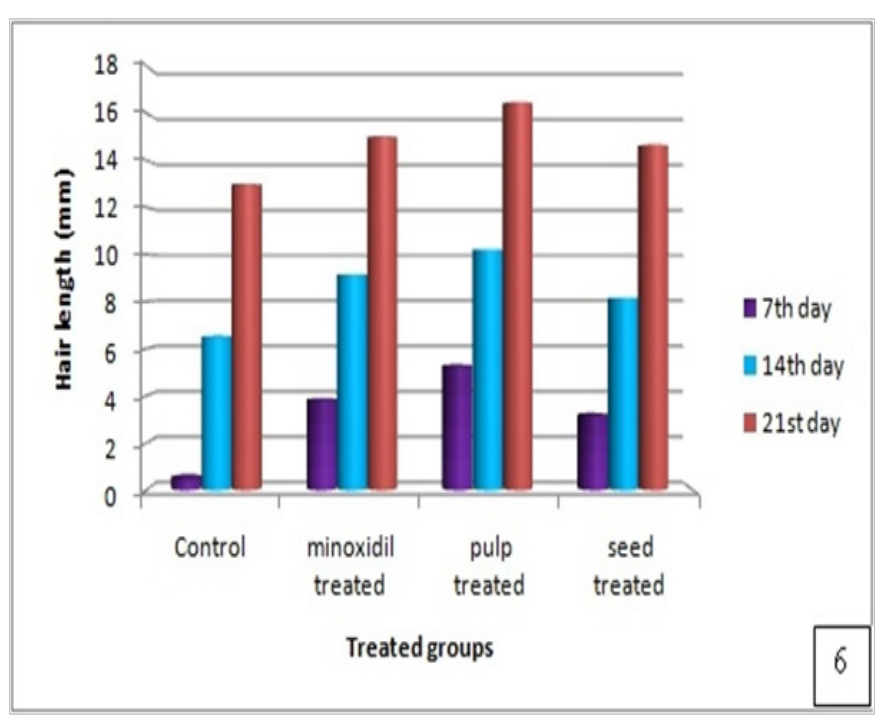

Figure 6 Graph showing the difference in hair length of the treated groups.

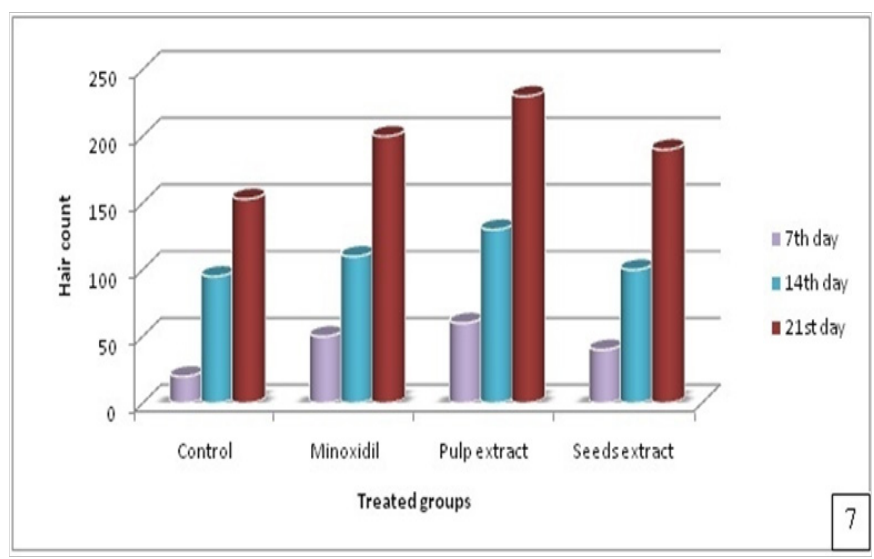

Figure 7 Graph showing the difference in the hair count of the treated groups.

Table 3 Effect of extracts ointments on the hair length

\section{No. Treatment Length of hair $(\mathrm{mm})$}

Day $7^{\text {th }} \quad$ Day $14^{\text {th }} \quad$ Day $21^{\text {st }}$

\begin{tabular}{lllll}
\hline & Control & $0.5 \pm 0.032$ & $6.5 \pm 0.276$ & $13 \pm 0.141$ \\
2 & Minoxidil (2\%) & $3.8 \pm 0.263^{*}$ & $9.16 \pm 0.196^{*}$ & $15.02 \pm 0.177^{*}$ \\
3 & $\begin{array}{l}\text { Pulp (Ethanolic } \\
\text { Extract) }\end{array}$ & $5.26 \pm 0.218^{*}$ & $10.22 \pm 0.367^{*}$ & $16.46 \pm 0.196^{*}$ \\
4 & $\begin{array}{l}\text { Seeds (Ethanolic } \\
\text { Extract) }\end{array}$ & $3.16 \pm 0.225^{*}$ & $8.14 \pm 0.196^{*}$ & $14.66 \pm 0.129^{*}$ \\
\hline
\end{tabular}

Results are expressed as Mean $+\mathrm{SEM}, \mathrm{n}=5, * \mathrm{P}<0.01$ when group were compared to control group by one way ANOVA, following Dunnet's multiple comparison test. 
Table 4 Effect of extracts ointments on the hair count

\begin{tabular}{lllll}
\hline & & \multicolumn{3}{c}{ Hair Count } \\
\cline { 3 - 5 } S. No. & Treatment & Day 7 th & Day 14 ${ }^{\text {th }}$ & Day 2 I ${ }^{\text {st }}$ \\
\hline I. & Control & $20 \pm 0.894$ & $95 \pm 3.538$ & $153 \pm 0.949$ \\
2. & Minoxidil (2\%) & $50 \pm 1.612^{*}$ & $110 \pm 1.703^{*}$ & $200 \pm 1.703^{*}$ \\
3. & $\begin{array}{l}\text { Pulp (ethanolic } \\
\text { extract) }\end{array}$ & $60 \pm 0.632^{*}$ & $130 \pm 2.025^{*}$ & $230 \pm 0.707^{*}$ \\
4. & $\begin{array}{l}\text { Seeds } \\
\text { (ethanolic } \\
\text { extract) }\end{array}$ & $40 \pm 3.536 *$ & $100 \pm 1.581$ & $190 \pm 1.703^{*}$ \\
\hline
\end{tabular}

Results are expressed as Mean+SEM, $* \mathrm{P}<0.01$ when group were compared to control group by one way ANOVA, following Dunnet's multiple comparison test.

Table 5 Characteristic of ointments

\begin{tabular}{llll}
\hline S.No. & Characters & $\begin{array}{l}\text { Fruit pulp } \\
\text { ointment }\end{array}$ & Seeds ointment \\
\hline 1 & Colour & Light yellow & Dark yellow \\
2 & Odour & Characteristic & None \\
3 & Taste & Sweet - astringent & Bitter \\
\hline
\end{tabular}

\section{Discussion}

Recently, the number of men and women who are suffering from hair loss/or hair thinning is increasing day by day. The demand for drugs that alter hair growth has led to multibillion dollar industry, probably due to the social stigma attached with baldness in males, as well as in females. In United States, hair loss sufferers spend more than 3.5billion dollars a year for treating this ailment. ${ }^{18,19}$ Because of the increasing popularity of the herbal drugs in hair care, it is considered worthwhile to take up systematic investigation on the efficacy of these herbal drugs and their preparations. Eugenia jambolana, one of the widely used medicinal plants in medicine, is well known to have many medicinal uses. These include being an anti-diabetic, hepatoprotective, anti-allergic etc. ${ }^{18}$ In the present study, Eugenia jambolana seeds and pulp extracts were evaluated for hair growth activity, in which four parameters were chosen; the hair initiation time, hair completion time, hair length and hair count. Overall, the results of the present research work exhibits encouraging hair growth promoting effect of Eugenia jambolana seed and fruit pulp extracts. The authors recommend in depth future studies regarding isolation of bioactive moieties and exploration of its mechanism of action.

\section{Acknowledgements}

None.

\section{Conflict of interest}

The author declares no conflict of interest.

\section{References}

1. Damodaran RG, Gupta R. Hair loss and the applied techniques for identification of novel hair growth promoters for hair regrowth. Phcog J. 2011;3(22):1-5.

2. Jadhav VM, Thorat RM, Kadam VJ, et al. Hair vitalizing herbs. International Journal of PharmTech Research. 2009;1(3):454-467.

3. Hunt N, McHale S. The psychological impact of alopecia. The Psychologist. 2007;20:362-364.

4. Sawant N, Chikhalkar S, Mehta V, et al. Androgenetic alopecia: qualityof-life and associated lifestyle patterns. Int J Trichology. 2010;2(2):8185 .

5. Stough D, Stenn K, Haber R, et al. Psychological effect, pathophysiology, and management of androgenetic alopecia in men. Mayo Clin Proc. 2005;80:1316-1322.

6. Kirtikar KR, Basu BD. Indian Medicinal Plants. 2nd ed. Orient enterprises, Dehradun (Uttaranchal), India; 2012.

7. Harborne JB. Phytochemical Methods: A Guide to modern techniques of plant analysis. 3rd ed. New Delhi, India: Springer Publishers; 2005.

8. Wagner H, Bladt S. Plant drug analysis $-A$ Thin Layer Chromatography Atlas. 2nd ed. New Delhi, India: Springer Verlag Berlin Hiedelberg; 1996.

9. Ahmed F, Huded S, Malik FA. In vitro study on the radical scavenging and anti-lipid peroxidative effects of Eugenia jambolana aqueous extracts. Journal of Pharmacy Research. 2010;3(1):198-200.

10. Brito FA, Lima LA, Ramos MFS, et al. Pharmacological study of antiallergic activity of Syzygium cumini (L) Skeels. Braz J Med Biol Res. 2007;40(1):105-115.

11. Chaturvedi A, Kumar MM, Bhawani G, et al. Effect of ethanolic extract of Eugenia jambolana seeds on gastric ulceration and secretion in rats. Indian J Physiol Pharmacol. 2007;51(2):131-140.

12. Cooper, Gunn. Dispensing for Pharmaceutical Students. 12th ed. New Delhi, India: Pitman Publishing Limited; 1975.

13. Suraj R, Rejitha G, Sunilson JAJ, et al. In vivo hair growth activity of Prunus dulcis seeds in rats. Biology and Medicine. 2009;1(4):34-38.

14. Saraf S, Pathak AK, Dixit VK. Hair growth promoting activity of Tridax procumbens. Fitoterapia. 1991;62(6):495-498.

15. Adhirajan N, Kumar TR, Shanmugasundaram N, et al. In vivo and In vitro evaluation of hair growth potential of Hibiscus rosa-sinensis Linn. J Ethnopharmacol. 2003;88(2-3):235-239.

16. Roy RK, Thakur M, Dixit VK. Development and evaluation of polyherbal formulation for hair growth-promoting activity. $J$ Cosmet Dermatol. 2007;6(2):108-112.

17. Semalty M, Semalty A, Joshi GP, et al. In vivo Hair growth activity of herbal formulations. International Journal of Pharmacology. 2010;6(1):53-57.

18. Roh SS, Kim CD, Lee MH, et al. The hair growth promoting effect of Sophora flavescens extract and its molecular regulation. J Dermatol Sci. 2002;30(1):43-49.

19. Datta K, Singh AT, Mukherjee A, et al. Eclipta alba extract with potential for hair growth promoting activity. J Ethnopharmacol. 2009;124(3):450 456. 